\title{
Progress in Defining the Genetic Basis of Diabetic Complications
}

\author{
Dahlstrom, Emma
}

2017-09

Dahlstrom , E \& Sandholm , N 2017 , ' Progress in Defining the Genetic Basis of Diabetic

Complications ' , Current diabetes reports. , vol. 17 , no. 9 , 80 . https://doi.org/10.1007/s11892-017-0906-z

http://hdl.handle.net/10138/241363

https://doi.org/10.1007/s11892-017-0906-z

unspecified

publishedVersion

Downloaded from Helda, University of Helsinki institutional repository.

This is an electronic reprint of the original article.

This reprint may differ from the original in pagination and typographic detail.

Please cite the original version. 


\title{
Progress in Defining the Genetic Basis of Diabetic Complications
}

\author{
Emma Dahlström ${ }^{1,2,3} \cdot$ Niina Sandholm ${ }^{1,2,3}$
}

Published online: 4 August 2017

(C) Springer Science+Business Media, LLC 2017

\begin{abstract}
Purpose of Review Diabetic complications affecting the kidneys, retina, nerves, and the cardiovasculature are the major causes of morbidity and mortality in diabetes. This paper aims to review the current understanding of the genetic basis of these complications, based on recent findings especially from genome-wide association studies.

Recent Findings Variants in or near AFF3, RGMA-MCTP2, SP3-CDCA7, GLRA3, CNKSR3, and UMOD have reached genome-wide significance ( $p$ value $<5 \times 10^{-8}$ ) for association with diabetic kidney disease, and recently, GRB2 was reported to be associated at genome-wide significance with diabetic retinopathy. While some loci affecting cardiovascular disease in the general population have been replicated in diabetes, GLUL affects the risk of cardiovascular disease specifically in diabetic subjects.

Summary Genetic findings are emerging for diabetic complications, although the studies remain relatively small compared to those for type 1 and type 2 diabetes. In addition to pinpointing specific loci, the studies also reveal biological information on correlated traits and pathways.
\end{abstract}

This article is part of the Topical Collection on Genetics

Niina Sandholm

niina.sandholm@helsinki.fi

1 Folkhälsan Institute of Genetics, Folkhälsan Research Center, Haartmaninkatu 8, 00290 Helsinki, Finland

2 Abdominal Center Nephrology, University of Helsinki and Helsinki University Hospital, Helsinki, Finland

3 Research Program Unit, Diabetes and Obesity, University of Helsinki, Helsinki, Finland
Keywords Genetic risk factors · Diabetic complications · Genome-wide association study · End-stage renal disease . Diabetic retinopathy $\cdot$ Cardiovascular disease

\section{Introduction}

Diabetic complications are a major cause of morbidity and mortality $[1,2]$. While macrovascular complications affect the coronary, cerebral, and peripheral arteries, microvascular complications cause diabetic kidney disease (DKD) leading to renal failure, diabetic retinopathy (DR) leading to blindness, and peripheral and autonomic neuropathy [3].

Elevated blood glucose levels, measured as glycated hemoglobin $\left(\mathrm{HbA}_{1 \mathrm{C}}\right)$, are a major risk factor for both micro- and macrovascular complications [3]. In addition to clinical risk factors, genetic factors affect the risk as well. Besides improving our understanding of the mechanisms leading to disease, pinpointing the genetic risk factors also holds the promise of revealing novel biomarkers for early detection of patients at highest risk, and novel druggable target molecules for future treatment. For example, PCSK9 inhibitors, a novel group of low-density lipoprotein (LDL) cholesterol lowering drugs that reduce the risk of cardiovascular disease (CVD), are based on genetic discovery [4]. Even though the genetic background remains relatively poorly understood, genetic findings for diabetic complications are starting to emerge. The key findings, as well as the main challenges and future directions for the genetic discovery for diabetic complications, are reviewed in this article. 


\section{Renal Complications in Diabetes}

DKD is a devastating complication affecting one third of the subjects with type 1 diabetes (T1D) [5]. Classically, DKD is described to commence with microalbuminuria (i.e., urinary excretion of low concentrations of albumin), leading to macroalbuminuria (urinary excretion of considerable amounts of albumin), then leading to a decrease in the (estimated) glomerular filtration rate (eGFR). However, loss of renal function can also appear without albuminuria [6]. Despite improved medical care, $2-20 \%$ of subjects with T1D develop endstage renal disease (ESRD) that requires dialysis or a renal transplant [7, 8], and is associated with 14-fold risk of mortality compared with diabetic subjects without renal complications [2].

DKD clusters in families, with a twofold sibling recurrence risk [9-11]. Heritability estimates for albuminuria in type 2 diabetes (T2D) range from 30 to $45 \%$ [12,13], and for eGFR they reach up to $75 \%$ [13]. Recently, genome-wide genotyping data of unrelated individuals has been utilized to estimate the narrow sense heritability $h^{2}$, i.e., the phenotypic variance explained by the additive effects of genotyped single nucleotide polymorphisms (SNPs) for albuminuria $\left(h^{2}=27 \%\right.$ [14••]), and for case-control phenotypes in T1D: $h^{2}$ was $35 \%$ for albuminuria-based DKD, $47 \%$ for eGFR-based chronic kidney disease (CKD; defined as eGFR $<60 \mathrm{ml} / \mathrm{min} /$ $1.73 \mathrm{~m}^{2}$ ), and $59 \%$ for the composite phenotype of both DKD and CKD [15••].

\section{Candidate Genes for DKD}

Plenty of candidate genes have been considered for DKD, with the largest number of studies investigating an insertion/ deletion polymorphism rs1799752 (tagged by rs4344) in the $A C E$ gene encoding the angiotensin-converting enzyme (ACE) $[16,17]$. ACE inhibitors are the principal treatment for DKD and other proteinuric renal diseases, along with other medications targeting the renin-angiotensin-aldosterone system (RAAS). Despite the inclusion of over 26,000 subjects in the literature-based meta-analysis, only modest evidence of association was found $[16,17]$. As it is characteristic of many candidate gene studies, the vast majority of the 63 included studies had only tens to few hundreds of participants [17]. A literature-based meta-analysis of all candidate genes for DKD found evidence of association in 17 loci. However, the analysis did not consider correction for multiple testing or apply particularly stringent significance thresholds [16]. The candidate genes were subsequently evaluated in a meta-analysis of three large cohorts from the "Genetics of Nephropathy - an International Effort" (GENIE) Consortium with up to 6366 subjects with T1D. No association remained significant after correction for multiple testing, suggesting that many previous findings were false positives, and highlighting the need for hypothesis-free genome-wide association studies (GWAS) performed in large and well-characterized study populations [18].

\section{GWAS on DKD}

GWAS have proven efficient in detecting genetic loci associated with common diseases: for example, over 80 loci have been identified for T2D to date [19]. Although the number of loci for DKD remains modest, the number of genome-wide significant findings for DKD is increasing (Table 1).

Before the currently used GWAS arrays that genotype hundreds of thousands of SNPs, a GWAS covering 80,000 polymorphisms in 188 subjects with T2D suggested an association in the ELMO1 gene $\left(p=8 \times 10^{-6}\right)$ [20], but replication remains controversial despite evaluation in multiple cohorts $[15 \bullet \bullet, 18,32,33]$. GWAS on DKD including 1705 subjects with T1D from the US Genetics of Kidneys in Diabetes (GoKinD) collection identified four loci with a suggestive $p$ value $<10^{-5}$ and found supporting evidence of association for variants near FRMD3 and CARS genes in the Diabetes Control and Complications Trial (DCCT)/Epidemiology of Diabetes Interventions and Complications (EDIC) Study [22]. With some subsequent studies supporting these findings and others not $[18,34,35]$, replication remains inconclusive as the association has not reached genome-wide statistical significance, defined as $p$ value $<5 \times 10^{-8}$, required for robust association due to the burden of multiple testing in GWAS.

The first genome-wide significant findings were obtained from a meta-analysis of three GWAS from the GENIE consortium, with up to 11,847 subjects with T1D including replication studies. Variants in AFF3 $\left(p=1.2 \times 10^{-8}\right)$ and between the RGMA and MCTP2 genes $\left(p=2.0 \times 10^{-9}\right)$ were associated with ESRD. Functional work on renal epithelial cells suggested that $A F F 3$ affects the renal tubular fibrosis, a pathological feature of severe DKD. The RGMA/MCTP2 locus was also among the top findings in a subsequent study utilizing a data mining approach [27]. However, little is known about the flanking genes, and despite "naming" the locus based on the closest genes, the signal may target the expression or function of a gene located much further away [36]. For the DKD phenotype, suggestive association was found at the ERBB4 gene $\left(p=2.1 \times 10^{-7}\right)$ [25]. ERBB4 knock-out and overexpression mice show that this gene affects renal development [37]. Furthermore, pan-ErbB inhibitors protect from albuminuria in diabetic mouse models, potentially through ErbB4 [38].

Gender-stratified GWAS revealed variants on the SP3/ $C D C A 7$ gene region associated with twofold risk of ESRD in women with T1D $\left(p<5 \times 10^{-8}\right)$. The finding was replicated in other GENIE cohorts while no association was seen in men [26]. SP3 is a biologically plausible candidate, as the Sp3 transcription factor directly binds to the estrogen receptor $\alpha$ 


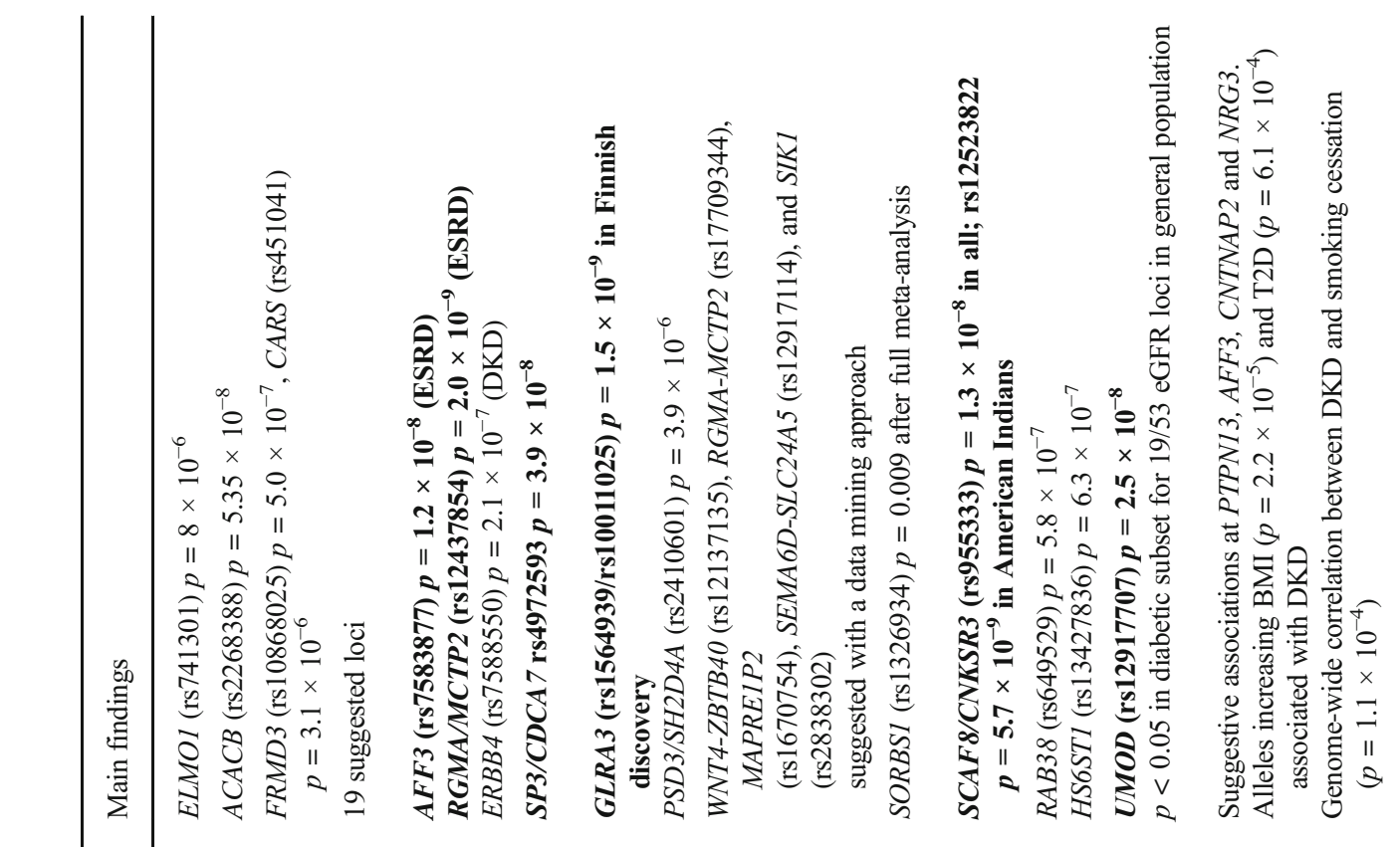

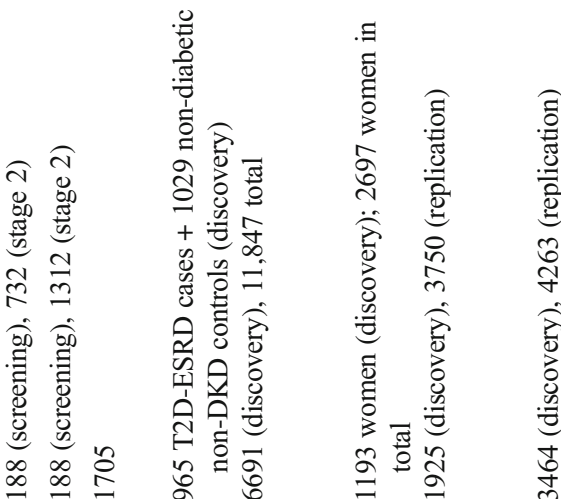

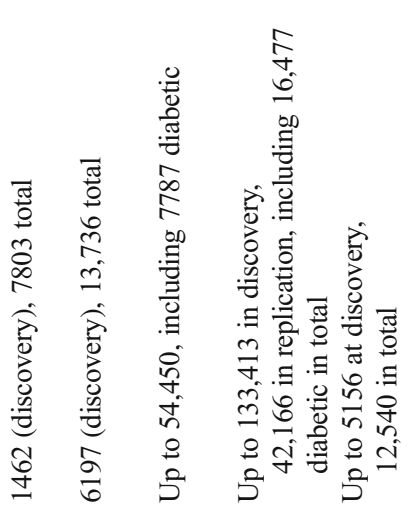

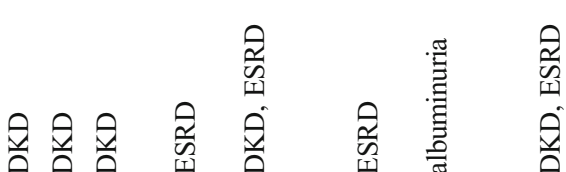

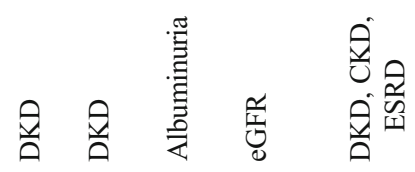

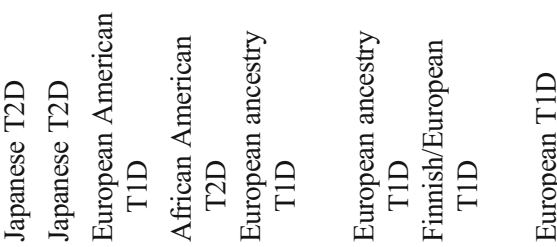

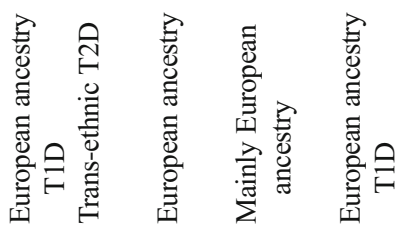

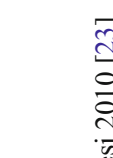

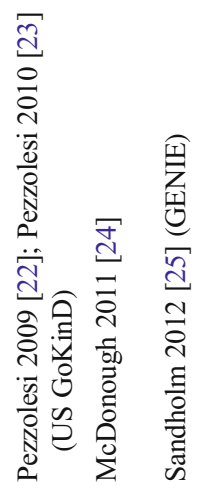

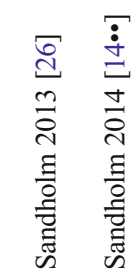

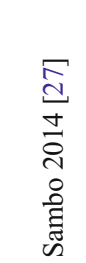

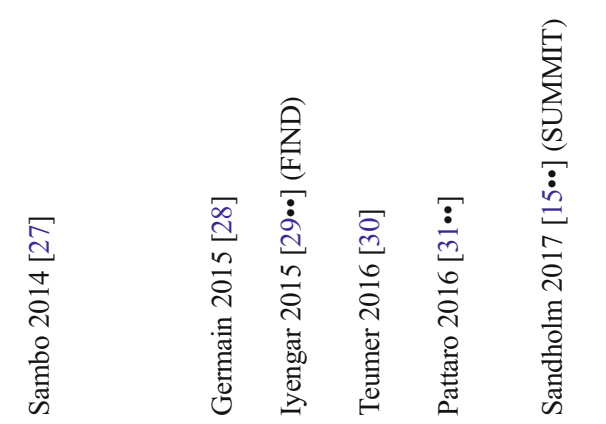

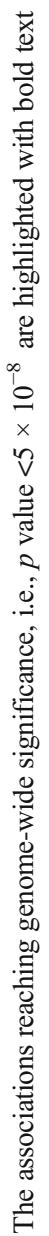


forming a protein complex activated by estrogen [39]; together with the notion that SP3 is more expressed in the glomeruli of diabetic women than men, this may explain why the association is limited to women [26].

A GWAS of albuminuria in 1925 Finnish subjects with T1D found variants in the GLRA3 gene with $p=1.5 \times 10^{-9}$. While nominally significant association was obtained in the meta-analysis of additional 3750 subjects with T1D and of European ancestry, the association was in the opposite direction. The authors suggest that the associated SNPs might be in linkage disequilibrium with population-specific variants, and therefore warrant replication in additional Finnish participants [26].

A trans-ethnic GWAS meta-analysis performed in the Family Investigation of Nephropathy and Diabetes (FIND) consortium identified variants associated with DKD between the SCAF8 and CNKSR3 genes $\left(p=5.7 \times 10^{-9}\right)$ [29••]. The association was particularly strong in American Indians. CNKSR3 encodes for a scaffolding platform that stimulates epithelial sodium channel in response to aldosterone [40], one of the main targets of the RAAS blockers used to treat DKD. Strong association was also seen in African Americans in the MYH9/APOL1 locus, an important genetic susceptibility locus for many non-diabetic renal diseases; the association in subjects with T2D is likely due to unrecognized nondiabetic renal disease co-occurring with T2D [29••, 35]. This highlights the challenge of phenotypic heterogeneity, particularly in subjects with T2D: while most subjects with T1D and albuminuria have pathological renal lesions characteristic of diabetic nephropathy, there is a spectrum of renal pathologies in subjects with T2D where only a third patients with albuminuria have typical diabetic nephropathy [41].

To tackle the challenge posed by phenotypic heterogeneity in DKD, seven albuminuria and/or eGFR-based phenotypic definitions were used in the GWAS meta-analysis from SUrrogate markers for Micro- and Macrovascular hard endpoints for Innovative diabetes Tools (SUMMIT) consortium, which included up to 12,540 subjects with T1D in the combined meta-analysis. Suggestive associations were found in the AFF3, PTPN13, CNTNAP2, and NRG3 loci, although no locus reached genome-wide significance [15••]. Among the previously identified loci, independent evidence of association was found, after exclusion of overlapping studies, for SIK1 [27] for ESRD. The genetic risk scores consisting of variants increasing BMI and the risk of T2D were associated with DKD, suggesting BMI and metabolic changes behind T2D as causal risk factors for DKD in T1D. This supports a previous Mendelian Randomization study reporting a causal link between BMI and DKD [42]. Furthermore, genome-wide LD-score regression analysis of the SUMMIT GWAS and other traits revealed genome-wide correlation in the genetic contribution to DKD and smoking cessation [15••], supporting epidemiological findings that smoking cessation is beneficial for avoiding DKD [43].

A GWAS with up to 54,450 subjects from the general population, including a subset of 7787 subjects with diabetes (mainly T2D), suggested HS6ST1 and RAB38/CTSC $\left(p<10^{-6}\right)$ as novel loci for albuminuria in subjects with, but not without diabetes [30]. The largest GWAS meta-analysis on eGFR and CKD in the general population included 133,413 individuals at the discovery stage, and identified 53 loci ( $p$ value $<5 \times 10^{-8}$ ) for kidney traits [31••]. In the subset of 16,477 subjects with diabetes, significant association ( $p$ value $=2.5 \times 10^{-8}$ ) was found for eGFR at rs12917707 at $U M O D$, a major susceptibility locus in the general population, and nominal associations $(p<0.05)$ were found at 19 of the 53 loci $[31 \bullet \bullet]$.

\section{Whole Exome Sequencing}

GWAS findings feature mainly common variants, as GWAS genotyping arrays are designed to capture common variation, and genotype imputation does not sufficiently capture rare variation. Therefore, sequencingbased methods are needed to investigate low-frequency (minor allele frequency [MAF] 1-5\%) and rare variants (MAF <1\%) not detected on GWAS genotyping chip platforms. While whole genome sequencing is already possible, targeting only the protein coding sequence (representing less than $2 \%$ of the genome) with whole exome sequencing (WES) significantly reduces the costs, thus allowing higher sequencing depth resulting in better quality genotypes, and higher numbers of samples to be sequenced to increase the statistical power. Based on WES data for T2D, a candidate gene evaluation of the RREB1 gene, an upstream regulator of RAAS, was undertaken in 529 African American cases with T2D and ESRD, and 535 controls without DKD and diabetes. Replication and trait segregation in diabetic subjects without ESRD and ESRD subjects without diabetes suggested that variants in RREB1 may modulate the risk of T2D, ESRD, and non-diabetic renal disease $\left(p=3.5 \times 10^{-7}\right.$ for rs9379084 for the combined T2D-ESRD phenotype), but further replication is warranted to confirm the findings, especially as variants in this gene were previously associated with T2D in a large GWAS meta-analysis [44].

WES efforts are emerging for DKD. WES of 997 subjects with T1D from the SUMMIT consortium did not reveal any variants, or genes enriched for rare or low-frequency variants with stringent statistical significance $\left(p<5 \times 10^{-7}\right)$ [15••]. Common variants in ERBB 4 were among the strongest associations for ESRD; variants in the same gene were suggestively associated with DKD in the GENIE GWAS, albeit a subset of the included subjects is overlapping [15••]. 


\section{DNA Methylation}

DNA methylation has been suggested as a potential explanation for "metabolic memory," a sustained effect of improved blood glucose levels [45•]. An early genome-wide DNA methylation study covering $25,578 \mathrm{CpG}$ sites in 192 participants with T1D identified 19 loci differentially methylated in blood of DKD cases versus controls without renal complications [46]. As the currently used DNA methylation chips can address hundreds of thousands of $\mathrm{CpG}$ sites [47•], a larger study could reveal more genes related to DKD methylation.

\section{Diabetic Retinopathy}

DR is one of the leading causes of blindness worldwide [48], affecting $30 \%$ of subjects with T2D [49] and 50$80 \%$ of subjects with T1D [49, 50]; among the T1D subjects with severe renal complications, nearly all have at least some level of diabetic retinal changes [2]. DR has the highest sibling recurrence risk of the microvascular diabetic complications [51], and the heritability estimates for DR range from 25 to $52 \%$ [52-56].

As for DKD, many candidate gene studies have been performed on DR, including meta-analyses, e.g., for $A C E$ [57], $A K R 1 B 1$ (encoding for aldose reductase) [58], and $V E G F$ (encoding for vascular endothelial growth factor) [59]. A systematic meta-analysis of 20 candidate genes for DR found the strongest evidence of association for the $\mathrm{z}-2$ microsatellite and rs 759853 on $A K R 1 B 1$ ( $p$ value $=1 \times 10^{-4}$ ) and nominally significant evidence for polymorphisms in NOS3, $V E G F$, ITGA2, and ICAM1 genes [60]. A large-scale multi-ethnic candidate gene study testing 49,320 SNPs from 2000 candidate genes found suggestive associations with $p$ value below $10^{-6}$, but the findings did not replicate [61]. In a meta-analysis of 1907 subjects with T1D, none of the previously reported loci remained significant after adjustment for multiple testing, suggesting that many of the previous reports may represent false positive findings [62].

In addition to partially shared pathophysiological mechanisms, there is evidence of a shared genetic background between DR and DKD [62]. Two candidate gene studies identified loci with genome-wide significance for a combined ESRD and DR phenotype after metaanalysis with replication cohorts; subsequent replication at the erythropoietin (EPO) gene [63] has been inconclusive $[18,62,64]$, whereas replication of a recent association $\left(p=7.1 \times 10^{-9}\right)$ in SLC19A3, a thiamin (vitamin $B_{1}$ ) transporter, has not yet been attempted in other studies [65•].

\section{GWAS on DR}

Multiple GWAS on DR have been published including studies in Mexican Americans [66], Taiwanese [67], Chinese [68], Japanese [69], and White Australian [70••] subjects with T2D, and in European American subjects with T1D [71] (Table 2). However, the numbers of subjects were small (a couple of hundreds up to 3000) and the results mostly suggestive. Four loci (HS6ST3, ARHGAP22, PLXDC2, and KIAA0825) reached genome-wide significance in a GWAS including 749 subjects with T2D, but no replication of the findings was attempted [67]. Subsequently, one study provided nominally significant associations $(p<0.05)$ at the PLXDC2 and ARHGAP22 loci [62]. While other replication efforts of the early GWAS findings supported associations in or near API5 $(p=0.0005)$ [73], CEP135 $\left(p=2 \times 10^{-5}\right)$ [74], $\operatorname{NPY} 2 R\left(p=3 \times 10^{-5}\right)$ [74], and INSR $\left(p=9 \times 10^{-4}\right)[75]$, the findings were mainly inconclusive $[62,70 \bullet \bullet, 73-76]$, and no systematic effort has been published to pool together the collective evidence for these and other suggested loci.

A recent GWAS in 844 white Australians with T2D found variants associated with severe non-proliferative DR near the $G R B 2$ gene, with directionally consistent replication in all three replication cohorts (both $\mathrm{T} 2 \mathrm{D}$ and $\mathrm{T} 1 \mathrm{D}$, and of European and Indian ancestry), resulting in a $p$ value of $4.2 \times 10^{-8}$ at the combined meta-analysis [70••]. GRB2 activates the MAPK pathway in response to insulin by binding the major insulin receptor substrate IRS-1, and GRB2 expression was found upregulated in the retina of the mouse model for retinopathy $[70 \bullet \bullet]$.

\section{Whole Exome Sequencing}

A small WES study of 43 Saudi subjects with diabetes without DR and 64 with DR identified three genes, $N M E 3$, LOC728699, and FASTK, with an excess of rare variants in subjects without DR (all $p$ values $<5 \times 10^{-8}$ ) [72•]. As for the more recent observations from GWAS, validation in other cohorts is still required to confirm the findings.

\section{DNA Methylation}

A recent study investigated the genome-wide methylation patterns in 28 cases with T1D and DR, in 30 diabetic controls, and in 7 converters who developed DR during the 6.3 years follow-up. Among the 485,577 $\mathrm{CpG}$ sites evaluated in the study, 349 sites at 233 unique loci were differentially methylated between the cases and controls. Among the 349 sites, 28 CpG sites were differentially methylated also between the DR controls and DR convertors [47•]. In addition to proposing novel genes for the pathology of DR, the authors suggested that DNA methylation patterns could be used as biomarkers to 
Table 2 Main GWAS, WES, and genome-wide methylation studies for DR

\begin{tabular}{|c|c|c|c|}
\hline Study & Population & $N$ & Main findings \\
\hline \multicolumn{4}{|l|}{ GWAS } \\
\hline Fu 2010 [66] & Mexican American T2D & 286 & 13 loci with $p<0.0001$ \\
\hline Huang $2011[67]$ & Taiwanese T2D & $\begin{array}{l}174 \text { T2D-DKD cases }+575 \text { T2D } \\
\text { controls; } 100 \text { non-diabetic controls }\end{array}$ & $\begin{array}{l}\text { KIAA0825 }(\mathrm{rs17376456}) p=3.0 \times 10^{-9} \\
\text { HS6ST3 }(\mathrm{rs2038823}) p=4.7 \times 10^{-11} \\
\text { ARHGAP22 }(\mathrm{rs4838605}) p=1.9 \times 10^{-9} \\
P L X D C 2(\mathrm{rs} 12219125) p=9.3 \times 10^{-9} \\
p \text { values are for best genetic models }\end{array}$ \\
\hline $\begin{array}{l}\text { Grassi } 2011[71] \\
\text { (EDIC + GoKinD } \\
\text { US) }\end{array}$ & European American T1D & 2829 & $\begin{array}{l}3 \text { loci with } p<10^{-6} \text { (AKT3, A2BP1, } \\
\text { LEKRI-VEPH1) }\end{array}$ \\
\hline $\begin{array}{l}\text { Sobrin } 2011[61] \\
\quad(\text { CARe })^{\mathrm{a}}\end{array}$ & $\begin{array}{l}\text { Multi-ethnic T2D, incl. T1D in } \\
\text { replication }\end{array}$ & $\begin{array}{l}2691 \text { (1254 European American) in } \\
\text { discovery, } 8041 \text { in replication }\end{array}$ & $\begin{array}{l}2 \text { loci with } p<10^{-6} \text { (SELP, IDUA), did not } \\
\text { replicate }\end{array}$ \\
\hline Sheu 2013 [68] & Chinese T2D & 1007 & 3 loci with $p<10^{-5}$, not replicated in Hispanics \\
\hline Awata 2014 [69] & Japanese T2D & 446 (discovery), 1986 in total & $\begin{array}{l}R P 1-90 L 14.1 / C E P 162(\mathrm{rs} 9362054) \\
\quad p=4.4 \times 10^{-8} \text { in stage } 1+2, p=1.4 \times 10^{-7} \\
\quad \text { in total }\end{array}$ \\
\hline Burdon $2015[70 \bullet \bullet$ & $\begin{array}{l}\text { White Australian T2D; } \\
\text { multi-ethnic replication in } \\
\text { T1D + T2D }\end{array}$ & 844 (discovery), 2494 total & $G R B 2(\mathrm{rs} 9896052) p=4.2 \times 10^{-8}$ \\
\hline \multicolumn{4}{|c|}{ Candidate gene studies for combined ESRD + DR phenotype } \\
\hline Tong 2008 [63] & European Ancestry T1D and T2D & 2572 in total from 3 cohorts & $E P O(\operatorname{rs1617640}) p=3 \times 10^{-11}$ \\
\hline Porta 2016 [65•] & European Ancestry T1D & 753 in total from 2 studies & $S L C 19 A 3(\operatorname{rs} 12694743) p=7.1 \times 10^{-9}$ \\
\hline \multicolumn{4}{|c|}{ Whole exome sequencing (WES) } \\
\hline Shtir 2016 [72•] & Saudi & 107 & $\begin{array}{l}\text { Excess of rare variants in NME3, LOC728699, } \\
\text { and FASTK }\left(p<5 \times 10^{-8}\right)\end{array}$ \\
\hline \multicolumn{4}{|c|}{ Genome-wide DNA methylation } \\
\hline Agardh 2015 [47•] & Swedish T1D & 28 cases, 30 controls, 7 converters & $\begin{array}{l}349 \text { CpG sites at } 233 \text { loci differentially } \\
\text { methylated (FDR < 0.05) }\end{array}$ \\
\hline
\end{tabular}

The associations reaching genome-wide significance, i.e., $p$ value $<5 \times 10^{-8}$ are highlighted with bold text

$F D R$ false discovery rate

${ }^{a}$ Large-scale candidate gene study testing 49,320 SNPs from $\sim 2000$ candidate genes

predict DR, but acknowledged that independent replication is first required to confirm the findings $[47 \bullet]$.

\section{Diabetic Neuropathy}

Diabetic neuropathy is a microvascular complication affecting the neurons, resulting in a spectrum of clinical manifestations such as neuropathic pain (peripheral neuropathy) and cardiac and gastrointestinal autonomic neuropathy. Familial clustering has been found for diabetic neuropathy, but more modest than for other microvascular complications [51]. A recent study utilized genome-wide genotype data to estimate $11 \%$ narrow sense heritability for diabetic neuropathic pain [77•]; when stratified by gender, narrow sense heritability was higher in males $(30 \%)$ than in females $(15 \%)$ [78].

Maybe because of the challenges to define the phenotype, only a few genetic studies have been performed on diabetic neuropathy. Although no systematic literature-based metaanalyses have been published on all candidate genes for diabetic neuropathy, meta-analyses have been performed for the insertion/deletion variant in $A C E[79,80]$ and a polymorphism in the methylenetetrahydrofolate reductase (MTHFR) gene [81], all showing nominal evidence of association with diabetic neuropathy.

Despite the small number of candidate gene studies, two GWAS have been published for neuropathic pain in diabetes based on 3063 subjects with T2D from the Genetics of Diabetes and Audit Research Tayside Study (GoDARTS) 
$[77 \bullet, 78]$. Cases were defined based on prescription of medicines, and positive monofilament test; $8 \%$ of the subjects filled these criteria of neuropathic pain [77•]. The GWAS found suggestive evidence of association at rs17428041 near the GFRA2 gene $\left(p=1.8 \times 10^{-7}\right)[77 \cdot]$. Subsequent analysis of the same study with somewhat relaxed participant inclusion criteria, including 4221 subjects, suggested association at rs 71647933 between the ZSCAN20 and TLR12P genes ( $p$ val$\mathrm{ue}=4.9 \times 10^{-7}, \mathrm{OR}=1.65,95 \%$ confidence interval $[\mathrm{CI}]$ 1.36-2.02). The same locus yielded also the strongest association in the female only dataset $\left(p\right.$ value $=2.7 \times 10^{-7}$, $\mathrm{OR}=2.31,95 \%$ CI 1.68-3.17; association was not significant in men). Among men, the strongest association was obtained at rs6986153, near to HMGB1P46 ( $p$ value $8.0 \times 10^{-7}$, $\mathrm{OR}=1.67,95 \%$ CI 1.34-2.08) [78]. As no replication was attempted, and the associations did not reach genome-wide significance, further evaluation of these loci in other cohorts is required to replicate these findings.

\section{Cardiovascular Complications in Diabetes}

CVD is the most common cause of death among patients with diabetes and atherosclerosis is central to its development [1]. Atherosclerosis occurs when a plaque consisting of substances found in the blood is built up in the arteries, resulting in narrowing of the arteries. Thus, blood flow is compromised to organs such as the heart muscle, the brain, and the extremities, causing the devastating cardiovascular complications known as coronary artery disease (CAD), cerebrovascular disease, and peripheral arterial disease (PAD).

Diabetes has been considered a "CVD equivalent," i.e., subjects with diabetes have the same risk of a cardiovascular event as subjects with pre-existing CVD [82]. The connection between DKD and CVD is particularly strong in T1D: $40 \%$ of patients with DKD develop CVD by the age of 40 , compared to $7 \%$ in patients without DKD [83]. CVD also occurs much earlier in life in T1D than in T2D, with a more rapid disease progression, and with women and men equally affected $[83$, 84]. However, among subjects with $\mathrm{T} 2 \mathrm{D}$, an adverse cardiovascular risk profile can be observed, even before diabetes diagnosis [85], whereas CVD is a longterm complication in T1D [83].

\section{Genetics Basis of Coronary Artery Disease}

Family history of CAD is an important risk factor for CAD both in the general population [86], and among insulin-treated subjects with diabetes [87], suggesting a genetic influence. In family studies in T2D, a heritability of $41 \%$ was attained for intima media thickness, a marker of subclinical atherosclerosis
[88]. Whereas many candidate gene studies for CAD have been undertaken in T2D subjects, e.g., for the $H P$ gene encoding haptoglobin $[89,90]$ with a milder effect also seen in subjects with T1D [91], relatively few have studied the genes involved in the development of CAD in T1D.

\section{GWAS on $C A D$}

To date, only one GWAS has been performed with the aim to identify genetic determinants of CAD specific to diabetes [92]. In the GWAS, which included 4188 participants with T2D from five cohorts, one variant (rs10911021) near GLUL, encoding a glutamine synthase, reached genome-wide significance $(\mathrm{OR}=1.36$, $p$ value $=2 \times 10^{-8}$ ). Additional analyses in a subset of 2374 non-diabetic participants found no association with CAD, suggesting rs10911021 is specific to subjects with diabetes. Furthermore, in the CARDIoGRAM consortium including 86,995 participants $(22,233$ cases, 64,762 controls) from the general population, rs 10911021 showed only a nominally significant association with CAD, which was likely to be driven by the proportion (15\%) of T2D participants within CARDIoGRAM [92]. Subsequent studies have replicated this finding for both incident CVD morbidity and mortality in T2D [93, 94].

Recently, analyses from a GWAS in the ACCORD trial revealed new risk loci that affect CVD mortality specifically in intensively treated participants with T2D [95•]. In the ACCORD trial, a decreased risk of nonfatal CVD events among intensively treated participants with $\mathrm{T} 2 \mathrm{D}(\mathrm{HbA} 1 \mathrm{c}<6.0 \%)$ was accompanied by a paradoxical rise in cardiovascular mortality. With a sample size of 2667 participants with T2D from the intensively treated arm of the ACCORD study, two loci, at 10q26 (rs9299870) and 5q13 (rs57922), attained genome-wide significance and both polymorphisms increased the risk of cardiovascular death threefold. Neither of the two loci were associated with CVD mortality in the standard treatment arm. However, the specific design and setting of the ACCORD study made replication of these findings particularly challenging.

In the general population, GWAS have successfully revealed $\sim 60$ distinct risk loci for CAD [96, 97•]. While some of these loci also associate with CAD in T2D (Fig. 1), the direction of effect is not always in line with that in the general population [98]. The joint effects of these CAD susceptibility polymorphisms have also been inconclusive [98-100], and larger studies are needed in diabetes. One locus that convincingly replicates in the presence of diabetes is a polymorphism on chromosome 9p21 [101], near CDKN2A and CDKN2B. It is associated with a $\sim 20 \%$ increased risk of CAD in 


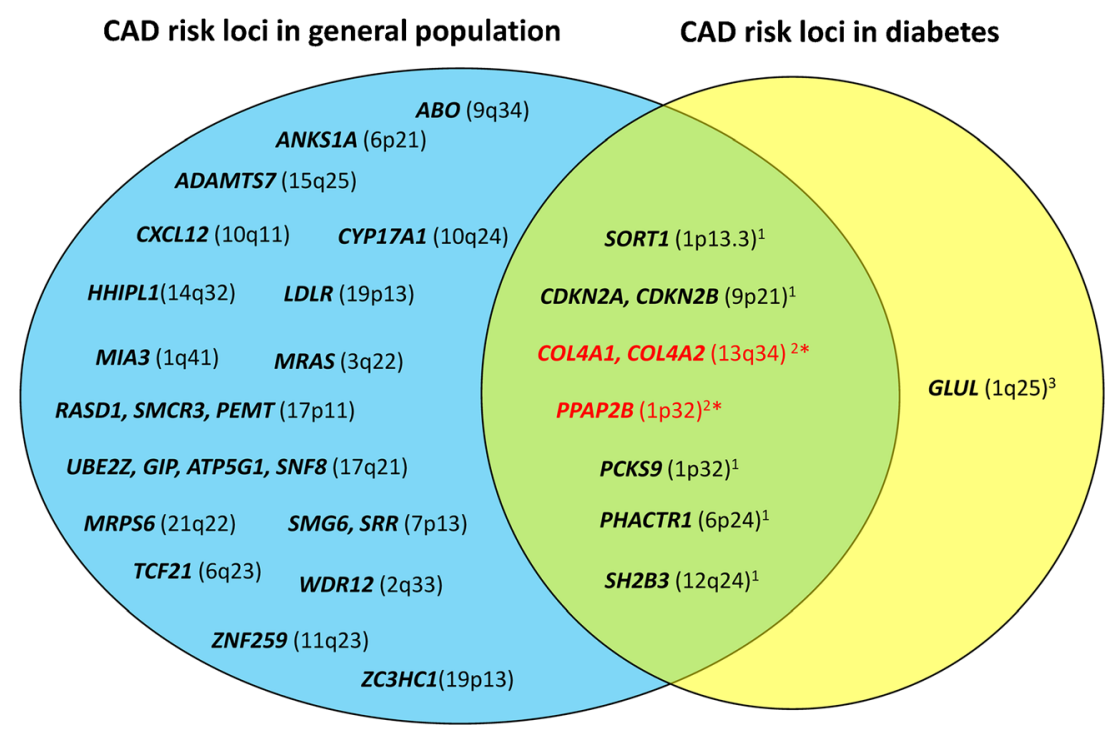

Fig. 1 CAD risk loci identified in GWAS in the general population and in subjects with diabetes. So far, only a subset of CAD risk loci from the general population have been found associated with CAD in the context of diabetes, and some of these associations go in the opposite direction* (13q34 and 1p24). Evaluation in larger studies with diabetic subjects may reveal more overlapping genes involved in the development of CAD in diabetes. The figure includes only genes that have been studied in subjects with diabetes. ${ }^{1}$ Associations with $p<0.05$ for CAD in Nurses Health Study (NHS), Health Professional Follow-up Study, Joslin Heart Study (JHS) as reported in Qi et al. 2011 [98]. ${ }^{2}$ Associations with $p<0.05$ for CAD in Diabetes Heart Study (DHS) as reported in supplement of Raffield et al. 2015 [99]. ${ }^{3} \mathrm{GWAS}$ locus for CAD in T2D reported from Qi et al. 2013 [92]
T2D [101], which is comparable to that in the general population [98, 102], and in the presence of poor glycemic control, the CAD risk for this locus is magnified in T2D [102]. However, it is currently not known whether 9 p21 or any of the other CAD risk loci identified in the general population also replicate in T1D.

\section{Genetic Basis of Cerebrovascular Disease}

The incidence of cerebrovascular disease, or stroke, is elevated among subjects with diabetes, particularly in the presence of other complications [83, 103]. Stroke consists mainly of ischemic strokes, but also hemorrhagic strokes [103]. Ischemic stroke can be further divided into large vessel disease, cardioembolic stroke, and small vessel disease, and recent GWAS in the general population on these subtypes suggest that different genetic factors are involved in different subtypes [104]. Genetic studies on stroke in diabetes are currently lacking; some of the genetic studies on cardiovascular complications in diabetes have included stroke in the composite CVD phenotype [90, 93, 94, 95•], but have not separately considered stroke or its subtypes.

\section{Genetic Basis of Peripheral Arterial Disease}

PAD is clinically observed as an aberrant ankle-brachial index, claudication, or critical limb ischemia, ultimately requiring amputation, particularly in subjects with diabetes [105].
Relatively few genetic risk loci that affect the development of PAD have been discovered, even in the general population. However, the 9p21 region associates with PAD in the general population [106] and preliminary findings from ongoing PAD GWAS suggest 9p21 also as a risk locus in diabetes, and highlight other polymorphisms that are only associated with PAD in diabetes [107].

\section{Conclusions}

There has been progress in defining the genetic basis of diabetic complications in the last 5 years, with the number of robustly identified susceptibility loci increasing. However, many challenges remain in the investigation of the genetic contribution to these complications.

A key challenge in genetic studies of all microvascular complications is the definition of the phenotype. Unprecise intermediate markers such as albuminuria or eGFR are used to assess renal function as renal biopsies cannot be taken for research purposes. Furthermore, various measures (e.g., albuminuria vs. eGFR), symptoms (neuropathic pain vs. peripheral neuropathy), and severity of symptoms complicate the study design and meta-analysis between studies. While heritability estimates may inform definition of sub-phenotypes [15••], there must be a balance between homogenizing the phenotype and reduction in number of subjects. 
The overlap between the genetic basis of CVD in the general population vs. in the diabetic subset remains unknown. As macrovascular complications (CAD, stroke) also exist in the general population, the same genetic risk factors may affect subjects with and without diabetes, with some additional diabetes-specific susceptibility loci (e.g., GLUL [92]). By contrast, diabetic nephropathy and retinopathy differ pathologically from kidney and retinal diseases in non-diabetic subjects; Even though the genetic risk factors for general kidney disease seem to also affect subjects with T2D to some extent [31••], this may be due to a considerable proportion of subjects with T2D having non-diabetic kidney disease (i.e., not diabetic nephropathy) $[29 \bullet \bullet, 35]$, and the genetic risk factors for DKD seem to substantially differ from the ones affecting the general population.

For DKD, GWAS meta-analyses of multiple cohorts already exist, and larger efforts are underway in subjects with T2D [108], and in $>20,000$ subjects with T1D [109]. By contrast, for DR, the participant numbers remain small and all but one published GWAS [71] are based on a single GWAS at the discovery stage; only one GWAS on CVD has been published in subjects with diabetes, and none in T1D. Larger data sets and international collaboration to combine genome-wide data across studies will be essential for discovery of novel loci and to clarify the role of previously reported signals. While whole exome and genome sequencing may reveal novel lowfrequency and rare variants for diabetic complications, the exome chip provides an alternative approach to targeting low-frequency variants at lower cost, making it feasible in larger cohorts [109]. Preliminary results from family-based approaches suggest novel loci as well [110].

Acknowledgements Niina Sandholm reports grants from Academy of Finland (299200), Folkhälsan Research Foundation, and Wilhelm and Else Stockmann Foundation. Emma Dahlström is supported by grants from Nylands Nation, the Waldemar von Frenckell Foundation, and the Finnish Diabetes Research Foundation.

\section{Compliance with Ethical Standards}

Conflict of Interest Emma Dahlström and Niina Sandholm declare that they have no conflict of interest.

Human and Animal Rights and Informed Consent All reported studies/experiments with human or animal subjects performed by the authors have been previously published and complied with all applicable ethical standards (including the Helsinki declaration and its amendments, institutional/national research committee standards, and international/national/institutional guidelines).

\section{References}

Papers of particular interest, published recently, have been highlighted as:

- Of importance

• Of major importance

1. Beckman JA, Creager MA, Libby P. Diabetes and atherosclerosis: epidemiology, pathophysiology, and management. JAMA. 2002;287(19):2570-81.

2. Groop PH, Thomas MC, Moran JL, Wadèn J, Thorn LM, Mäkinen VP, et al. The presence and severity of chronic kidney disease predicts all-cause mortality in type 1 diabetes. Diabetes. 2009;58(7):1651-8.

3. Forbes JM, Cooper ME. Mechanisms of diabetic complications. Physiol Rev. 2013;93(1):137-88.

4. Cohen JC, Boerwinkle E, Mosley TH Jr, Hobbs HH. Sequence variations in PCSK9, low LDL, and protection against coronary heart disease. N Engl J Med. 2006;354(12):1264-72.

5. Pambianco G, Costacou T, Ellis D, Becker DJ, Klein R, Orchard TJ. The 30-year natural history of type 1 diabetes complications: the Pittsburgh Epidemiology of Diabetes Complications Study experience. Diabetes. 2006;55(5):1463-9.

6. Molitch ME, Steffes M, Sun W, Rutledge B, Cleary P, de Boer IH, et al. Development and progression of renal insufficiency with and without albuminuria in adults with type 1 diabetes in the diabetes control and complications trial and the epidemiology of diabetes interventions and complications study. Diabetes Care. 2010;33(7): $1536-43$

7. Harjutsalo V, Maric C, Forsblom C, Thorn L, Waden J, Groop PH, et al. Sex-related differences in the long-term risk of microvascular complications by age at onset of type 1 diabetes. Diabetologia. 2011;54(8):1992-9.

8. The DCCT/EDIC Research Group, Nathan DM, Zinman B, Cleary PA, Backlund JY, Genuth S, et al. Modern-day clinical course of type 1 diabetes mellitus after 30 years' duration: the diabetes control and complications trial/epidemiology of diabetes interventions and complications and Pittsburgh epidemiology of diabetes complications experience (1983-2005). Arch Intern Med. 2009;169(14):1307-16.

9. Seaquist ER, Goetz FC, Rich S, Barbosa J. Familial clustering of diabetic kidney disease. N Engl J Med. 1989;320(18):1161-5.

10. Borch-Johnsen K, Norgaard K, Hommel E, Mathiesen ER, Jensen JS, Deckert T, et al. Is diabetic nephropathy an inherited complication. Kidney Int. 1992;41(4):719-22.

11. Harjutsalo V, Katoh S, Sarti C, Tajima N, Tuomilehto J. Population-based assessment of familial clustering of diabetic nephropathy in type 1 diabetes. Diabetes. 2004;53(9):2449-54.

12. Forsblom CM, Kanninen T, Lehtovirta M, Saloranta C, Groop LC. Heritability of albumin excretion rate in families of patients with type II diabetes. Diabetologia. 1999;42(11):1359-66.

13. Langefeld CD, Beck SR, Bowden DW, Rich SS, Wagenknecht LE, Freedman BI. Heritability of GFR and albuminuria in Caucasians with type 2 diabetes mellitus. Am J Kidney Dis. 2004;43(5):796-800.

14.• Sandholm N, Forsblom C, Makinen VP, McKnight AJ, Osterholm $\mathrm{AM}, \mathrm{He} \mathrm{B}$, et al. Genome-wide association study of urinary albumin excretion rate in patients with type 1 diabetes. Diabetologia. 2014;57(6):1143-53. The first GWAS on albuminuria as a continuous trait in T1D identified variants associated with albuminuria in Finnish subjects.

15.• Sandholm N, Van Zuydam N, Ahlqvist E, Juliusdottir T, Deshmukh HA, Rayner NW, et al. The genetic landscape of renal complications in type 1 diabetes. J Am Soc Nephrol. 2017;28(2): 
557-74. Heritability estimates, GWAS and WES on DKD in T1D, revealing also connections with related traits.

16. Mooyaart A, Valk EJJ, van Es L, Bruijn J, de Heer E, Freedman B, et al. Genetic associations in diabetic nephropathy: a meta-analysis. Diabetologia. 2011;54(3):544-53.

17. Wang F, Fang Q, Yu N, Zhao D, Zhang Y, Wang J, et al. Association between genetic polymorphism of the angiotensinconverting enzyme and diabetic nephropathy: a meta-analysis comprising 26,580 subjects. J Renin-Angiotensin-Aldosterone Syst. 2012;13(1):161-74.

18. Williams WW, Salem RM, McKnight AJ, Sandholm N, Forsblom $\mathrm{C}$, Taylor A, et al. Association testing of previously reported variants in a large case-control meta-analysis of diabetic nephropathy. Diabetes. 2012;61(8):2187-94.

19. DIAbetes Genetics Replication And Meta-analysis (DIAGRAM) Consortium, Asian Genetic Epidemiology Network Type 2 Diabetes (AGEN-T2D) Consortium, South Asian Type 2 Diabetes (SAT2D) Consortium, Mexican American Type 2 Diabetes (MAT2D) Consortium, Type 2 Diabetes Genetic Exploration by Nex-generation sequencing in muylti-Ethnic Samples (T2D-GENES) Consortium, Mahajan A, et al. Genome-wide trans-ancestry meta-analysis provides insight into the genetic architecture of type 2 diabetes susceptibility. Nat Genet. 2014;46(3):234-44.

20. Shimazaki A, Kawamura Y, Kanazawa A, Sekine A, Saito S, Tsunoda T, et al. Genetic variations in the gene encoding ELMO1 are associated with susceptibility to diabetic nephropathy. Diabetes. 2005;54(4):1171-8.

21. Maeda S, Kobayashi MA, Araki S, Babazono T, Freedman BI, Bostrom MA, et al. A single nucleotide polymorphism within the acetyl-coenzyme A carboxylase beta gene is associated with proteinuria in patients with type 2 diabetes. PLoS Genet. 2010;6(2): e1000842.

22. Pezzolesi MG, Poznik GD, Mychaleckyj JC, Paterson AD, Barati MT, Klein JB, et al. Genome-wide association scan for diabetic nephropathy susceptibility genes in type 1 diabetes. Diabetes. 2009;58(6):1403-10.

23. Pezzolesi MG, Skupien J, Mychaleckyj JC, Warram JH, Krolewski AS. Insights to the genetics of diabetic nephropathy through a genome-wide association study of the GoKinD collection. Semin Nephrol. 2010;30(2):126-40.

24. McDonough CW, Palmer ND, Hicks PJ, Roh BH, An SS, Cooke $\mathrm{JN}$, et al. A genome-wide association study for diabetic nephropathy genes in African Americans. Kidney Int. 2011;79(5):563-72.

25. Sandholm N, Salem RM, McKnight AJ, Brennan EP, Forsblom C, Isakova $\mathrm{T}$, et al. New susceptibility loci associated with kidney disease in type 1 diabetes. PLoS Genet. 2012;8(9):e1002921.

26. Sandholm N, McKnight AJ, Salem RM, Brennan EP, Forsblom C, Harjutsalo V, et al. Chromosome 2q31.1 associates with ESRD in women with type 1 diabetes. J Am Soc Nephrol. 2013;24(10): 1537-43.

27. Sambo F, Malovini A, Sandholm N, Stavarachi M, Forsblom C, Makinen VP, et al. Novel genetic susceptibility loci for diabetic end-stage renal disease identified through robust naive Bayes classification. Diabetologia. 2014;57(8):1611-22.

28. Germain M, Pezzolesi MG, Sandholm N, McKnight AJ, Susztak $\mathrm{K}$, Lajer M, et al. SORBS1 gene, a new candidate for diabetic nephropathy: results from a multi-stage genome-wide association study in patients with type 1 diabetes. Diabetologia. 2015;58(3): 543-8.

29.• Iyengar SK, Sedor JR, Freedman BI, Kao WH, Kretzler M, Keller BJ, et al. Genome-wide association and trans-ethnic meta-analysis for advanced diabetic kidney disease: Family Investigation of Nephropathy and Diabetes (FIND). PLoS Genet. 2015;11(8): e1005352. The first trans-ethnic GWAS meta-analysis for
DKD with genome-wide significant finding at $S C A F 8$ / CNKSR3 locus.

30. Teumer A, Tin A, Sorice R, Gorski M, Yeo NC, Chu AY, et al. Genome-wide association studies identify genetic loci associated with albuminuria in diabetes. Diabetes. 2016;65(3):803-17.

31.• Pattaro C, Teumer A, Gorski M, Chu AY, Li M, Mijatovic V, et al. Genetic associations at 53 loci highlight cell types and biological pathways relevant for kidney function. Nat Commun. 2016;7: 10023. The largest GWAS meta-analysis on kidney disease in the general population, with evaluation of the identified loci in a subset of diabetic patients.

32. Pezzolesi MG, Katavetin P, Kure M, Poznik GD, Skupien J, Mychaleckyj JC, et al. Confirmation of genetic associations at ELMO1 in the GoKinD collection supports its role as a susceptibility gene in diabetic nephropathy. Diabetes. 2009;58(11):2698702.

33. Leak TS, Perlegas PS, Smith SG, Keene KL, Hicks PJ, Langefeld $\mathrm{CD}$, et al. Variants in intron 13 of the ELMO1 gene are associated with diabetic nephropathy in African Americans. Ann Hum Genet. 2009;73(2):152-9.

34. Pezzolesi MG, Jeong J, Smiles AM, Skupien J, Mychaleckyj JC, Rich SS, et al. Family-based association analysis confirms the role of the chromosome 9q21.32 locus in the susceptibility of diabetic nephropathy. PLoS One. 2013;8(3):e60301.

35. Freedman BI, Langefeld CD, Lu L, Divers J, Comeau ME, Kopp JB, et al. Differential effects of MYH9 and APOL1 risk variants on FRMD3 association with diabetic ESRD in African Americans. PLoS Genet. 2011;7(6):e1002150.

36. Smemo S, Tena JJ, Kim KH, Gamazon ER, Sakabe NJ, GomezMarin C, et al. Obesity-associated variants within FTO form longrange functional connections with IRX3. Nature. 2014;507(7492): $371-5$.

37. Veikkolainen V, Naillat F, Railo A, Chi L, Manninen A, Hohenstein P, et al. ErbB4 modulates tubular cell polarity and lumen diameter during kidney development. J Am Soc Nephrol. 2012;23(1):112-22.

38. Lee HW, Khan SQ, Khaliqdina S, Altintas MM, Grahammer F, Zhao JL, et al. Absence of miR-146a in podocytes increases risk of diabetic glomerulopathy via up-regulation of ErbB4 and notch-1. J Biol Chem. 2017;292(2):732-47.

39. Stoner M, Wang F, Wormke M, Nguyen T, Samudio I, Vyhlidal C, et al. Inhibition of vascular endothelial growth factor expression in HEC1A endometrial cancer cells through interactions of estrogen receptor alpha and Sp3 proteins. J Biol Chem. 2000;275(30): 22769-79.

40. Soundararajan R, Ziera T, Koo E, Ling K, Wang J, Borden SA, et al. Scaffold protein connector enhancer of kinase suppressor of Ras isoform 3 (CNK3) coordinates assembly of a multiprotein epithelial sodium channel (ENaC)-regulatory complex. J Biol Chem. 2012;287(39):33014-25.

41. Fioretto P, Mauer M. Histopathology of diabetic nephropathy. Semin Nephrol. 2007;27(2):195-207.

42. Todd JN, Dahlstrom EH, Salem RM, Sandholm N, Forsblom C, FinnDiane Study Group, et al. Genetic evidence for a causal role of obesity in diabetic kidney disease. Diabetes. 2015;64(12): 4238-46.

43. Feodoroff M, Harjutsalo V, Forsblom C, Thorn L, Waden J, Tolonen N, et al. Smoking and progression of diabetic nephropathy in patients with type 1 diabetes. Acta Diabetol. 2016;53(4): 525-33.

44. Bonomo JA, Guan M, Ng MC, Palmer ND, Hicks PJ, Keaton JM, et al. The ras responsive transcription factor RREB1 is a novel candidate gene for type 2 diabetes associated end-stage kidney disease. Hum Mol Genet. 2014;23(24):6441-7.

45. Chen Z, Miao F, Paterson AD, Lachin JM, Zhang L, Schones DE, et al. Epigenomic profiling reveals an association between 
persistence of DNA methylation and metabolic memory in the DCCT/EDIC type 1 diabetes cohort. Proc Natl Acad Sci U S A. 2016;113(21):E3002-11. The study provides evidence that DNA methylation contributes to the sustained improved outcomes after intensive diabetes treatment.

46. Bell CG, Teschendorff AE, Rakyan VK, Maxwell AP, Beck S, Savage DA. Genome-wide DNA methylation analysis for diabetic nephropathy in type 1 diabetes mellitus. BMC Med Genet. 2010;3:33-8794-3-33.

47. Agardh E, Lundstig A, Perfilyev A, Volkov P, Freiburghaus T, Lindholm E, et al. Genome-wide analysis of DNA methylation in subjects with type 1 diabetes identifies epigenetic modifications associated with proliferative diabetic retinopathy. BMC Med. 2015;13:182-015-0421-5. The first genome-wide analysis of DNA methylation in diabetic retinopathy.

48. Resnikoff S, Pascolini D, Etya'ale D, Kocur I, Pararajasegaram R, Pokharel GP, et al. Global data on visual impairment in the year 2002. Bull World Health Organ. 2004;82(11):844-51.

49. Mathur R, Bhaskaran K, Edwards E, Lee H, Chaturvedi N, Smeeth L, et al. Population trends in the 10-year incidence and prevalence of diabetic retinopathy in the UK: a cohort study in the Clinical Practice Research Datalink 2004-2014. BMJ Open. 2017;7(2):e014444-2016-014444.

50. Roy MS, Klein R, O'Colmain BJ, Klein BE, Moss SE, Kempen $\mathrm{JH}$. The prevalence of diabetic retinopathy among adult type 1 diabetic persons in the United States. Arch Ophthalmol. 2004;122(4):546-51.

51. Monti MC, Lonsdale JT, Montomoli C, Montross R, Schlag E, Greenberg DA. Familial risk factors for microvascular complications and differential male-female risk in a large cohort of American families with type 1 diabetes. J Clin Endocrinol Metab. 2007;92(12):4650-5.

52. Hietala K, Forsblom C, Summanen P, Groop PH, FinnDiane Study Group. Heritability of proliferative diabetic retinopathy. Diabetes. 2008;57(8):2176-80.

53. Hallman DM, Huber JC Jr, Gonzalez VH, Klein BE, Klein R, Hanis CL. Familial aggregation of severity of diabetic retinopathy in Mexican Americans from Starr County, Texas. Diabetes Care. 2005;28(5):1163-8.

54. Rema M, Saravanan G, Deepa R, Mohan V. Familial clustering of diabetic retinopathy in South Indian type 2 diabetic patients. Diabet Med. 2002;19(11):910-6.

55. The DCCT Research Group. Clustering of long-term complications in families with diabetes in the diabetes control and complications trial. Diabetes. 1997;46(11):1829-39.

56. Arar NH, Freedman BI, Adler SG, Iyengar SK, Chew EY, Davis MD, et al. Heritability of the severity of diabetic retinopathy: the FIND-Eye study. Invest Ophthalmol Vis Sci. 2008;49(9):383945.

57. Luo S, Shi C, Wang F, Wu Z. Association between the angiotensin-converting enzyme (ACE) genetic polymorphism and diabetic retinopathy - a meta-analysis comprising 10,168 subjects. Int J Environ Res Public Health. 2016;13(11):E1142.

58. Zhou M, Zhang P, Xu X, Sun X. The relationship between aldose reductase $\mathrm{C} 106 \mathrm{~T}$ polymorphism and diabetic retinopathy: an updated meta-analysis. Invest Ophthalmol Vis Sci. 2015;56(4): 2279-89.

59. Xie XJ, Yang YM, Jiang JK, Lu YQ. Association between the vascular endothelial growth factor single nucleotide polymorphisms and diabetic retinopathy risk: a meta-analysis. J Diabetes. 2017;9(8):738-53.

60. Abhary S, Hewitt AW, Burdon KP, Craig JE. A systematic metaanalysis of genetic association studies for diabetic retinopathy. Diabetes. 2009;58(9):2137-47.

61. Sobrin L, Green T, Sim X, Jensen RA, Tai ES, Tay WT, et al. Candidate gene association study for diabetic retinopathy in persons with type 2 diabetes: the Candidate gene Association Resource (CARe). Invest Ophthalmol Vis Sci. 2011;52(10): 7593-602.

62. Hosseini SM, Boright AP, Sun L, Canty AJ, Bull SB, Klein BE, et al. The association of previously reported polymorphisms for microvascular complications in a meta-analysis of diabetic retinopathy. Hum Genet. 2015;134(2):247-57.

63. Tong Z, Yang Z, Patel S, Chen H, Gibbs D, Yang X, et al. Promoter polymorphism of the erythropoietin gene in severe diabetic eye and kidney complications. Proc Natl Acad Sci U S A. 2008;105(19):6998-7003.

64. Abhary S, Burdon KP, Casson RJ, Goggin M, Petrovsky NP, Craig JE. Association between erythropoietin gene polymorphisms and diabetic retinopathy. Arch Ophthalmol. 2010;128(1): 102-6.

65. Porta M, Toppila I, Sandholm N, Hosseini SM, Forsblom C, Hietala K, et al. Variation in SLC19A3 and protection from microvascular damage in type 1 diabetes. Diabetes. 2016;65(4): 1022-30. Candidate gene study on thiamin transporters with a genome-wide significant association for a composite phenotype of ESRD and DR.

66. Fu YP, Hallman DM, Gonzalez VH, Klein BE, Klein R, Hayes $\mathrm{MG}$, et al. Identification of diabetic retinopathy genes through a genome-wide association study among Mexican-Americans from Starr County, Texas. J Ophthalmol. 2010; doi:10.1155/2010/ 861291.

67. Huang YC, Lin JM, Lin HJ, Chen CC, Chen SY, Tsai CH, et al. Genome-wide association study of diabetic retinopathy in a Taiwanese population. Ophthalmology. 2011;118(4):642-8.

68. Sheu WH, Kuo JZ, Lee IT, Hung YJ, Lee WJ, Tsai HY, et al. Genome-wide association study in a Chinese population with diabetic retinopathy. Hum Mol Genet. 2013;22(15):3165-73.

69. Awata T, Yamashita H, Kurihara S, Morita-Ohkubo T, Miyashita Y, Katayama S, et al. A genome-wide association study for diabetic retinopathy in a Japanese population: potential association with a long intergenic non-coding RNA. PLoS One. 2014;9(11): e111715.

70.• Burdon KP, Fogarty RD, Shen W, Abhary S, Kaidonis G, Appukuttan B, et al. Genome-wide association study for sightthreatening diabetic retinopathy reveals association with genetic variation near the GRB2 gene. Diabetologia. 2015;58(10):228897. GWAS on retinopathy with genome-wide significant findings in GRB2 after multi-ethnic replication.

71. Grassi MA, Tikhomirov A, Ramalingam S, Below JE, Cox NJ, Nicolae DL. Genome-wide meta-analysis for severe diabetic retinopathy. Hum Mol Genet. 2011;20(12):2472-81.

72. Shtir C, Aldahmesh MA, Al-Dahmash S, Abboud E, Alkuraya H, Abouammoh MA, et al. Exome-based case-control association study using extreme phenotype design reveals novel candidates with protective effect in diabetic retinopathy. Hum Genet. 2016;135(2):193-200. The first whole-exome sequencing study on DR suggesting excess of rare variants in three genes resulting in protection from $D R$.

73. Peng D, Wang J, Zhang R, Jiang F, Tang S, Chen M, et al. Common variants in or near ZNRF1, COLEC12, SCYL1BP1 and API5 are associated with diabetic retinopathy in Chinese patients with type 2 diabetes. Diabetologia. 2015;58(6):1231-8.

74. Grassi MA, Tikhomirov A, Ramalingam S, Lee KE, Hosseini SM, Klein BE, et al. Replication analysis for severe diabetic retinopathy. Invest Ophthalmol Vis Sci. 2012;53(4):2377-81.

75. Cheung CY, Hui EY, Lee CH, Kwok KH, Gangwani RA, Li KK, et al. Impact of genetic loci identified in genome-wide association studies on diabetic retinopathy in Chinese patients with type 2 diabetes. Invest Ophthalmol Vis Sci. 2016;57(13):5518-24. 
76. McAuley AK, Wang JJ, Dirani M, Connell PP, Lamoureux E, Hewitt AW. Replication of genetic loci implicated in diabetic retinopathy. Invest Ophthalmol Vis Sci. 2014;55(3):1666-71.

77. Meng W, Deshmukh HA, van Zuydam NR, Liu Y, Donnelly LA, Zhou K, et al. A genome-wide association study suggests an association of Chr8p21.3 (GFRA2) with diabetic neuropathic pain. Eur J Pain. 2015;19(3):392-9. First GWAS on diabetic neuropathy.

78. Meng W, Deshmukh HA, Donnelly LA, Wellcome Trust Case Control Consortium 2 (WTCCC2), Surrogate markers for Micro- and Macro-vascular hard endpoints for Innovative diabetes Tools (SUMMIT) study group, Torrance N, et al. A genome-wide association study provides evidence of sex-specific involvement of Chr1p35.1 (ZSCAN20-TLR12P) and Chr8p23.1 (HMGB1P46) with diabetic neuropathic pain. EBioMedicine. 2015;2(10):1386-93.

79. Li Y, Tong N. Angiotensin-converting enzyme I/D polymorphism and diabetic peripheral neuropathy in type 2 diabetes mellitus: a meta-analysis. J Renin-Angiotensin-Aldosterone Syst. 2015;16(4):787-92.

80. Xu W, Qian Y, Zhao L. Angiotensin-converting enzyme I/D polymorphism is a genetic biomarker of diabetic peripheral neuropathy: evidence from a meta-analysis. Int J Clin Exp Med. 2015;8(1):944-8.

81. Wu S, Han Y, Hu Q, Zhang X, Cui G, Li Z, et al. Effects of common polymorphisms in the MTHFR and ACE genes on diabetic peripheral neuropathy progression: a meta-analysis. Mol Neurobiol. 2017;54(4):2435-44.

82. Emerging Risk Factors Collaboration, Sarwar N, Gao P, Seshasai SR, Gobin R, Kaptoge S, et al. Diabetes mellitus, fasting blood glucose concentration, and risk of vascular disease: a collaborative meta-analysis of 102 prospective studies. Lancet. 2010;375(9733):2215-22.

83. Tuomilehto J, Borch-Johnsen K, Molarius A, Forsen T, Rastenyte $\mathrm{D}$, Sarti C, et al. Incidence of cardiovascular disease in type 1 (insulin-dependent) diabetic subjects with and without diabetic nephropathy in Finland. Diabetologia. 1998;41(7):784-90.

84. de Ferranti SD, de Boer IH, Fonseca V, Fox CS, Golden SH, Lavie $\mathrm{CJ}$, et al. Type 1 diabetes mellitus and cardiovascular disease: a scientific statement from the American Heart Association and American Diabetes Association. Circulation. 2014;130(13): 1110-30

85. Hu FB, Stampfer MJ, Haffner SM, Solomon CG, Willett WC, Manson JE. Elevated risk of cardiovascular disease prior to clinical diagnosis of type 2 diabetes. Diabetes Care. 2002;25(7):112934.

86. Myers RH, Kiely DK, Cupples LA, Kannel WB. Parental history is an independent risk factor for coronary artery disease: the Framingham study. Am Heart J. 1990;120(4):963-9.

87. Earle K, Walker J, Hill C, Viberti G. Familial clustering of cardiovascular disease in patients with insulin-dependent diabetes and nephropathy. N Engl J Med. 1992;326(10):673-7.

88. Lange LA, Bowden DW, Langefeld CD, Wagenknecht LE, Carr JJ, Rich SS, et al. Heritability of carotid artery intima-medial thickness in type 2 diabetes. Stroke. 2002;33(7):1876-81.

89. Levy AP, Hochberg I, Jablonski K, Resnick HE, Lee ET, Best L, et al. Haptoglobin phenotype is an independent risk factor for cardiovascular disease in individuals with diabetes: the Strong Heart Study. J Am Coll Cardiol. 2002;40(11):1984-90.

90. Adams JN, Cox AJ, Freedman BI, Langefeld CD, Carr JJ, Bowden DW. Genetic analysis of haptoglobin polymorphisms with cardiovascular disease and type 2 diabetes in the Diabetes Heart Study. Cardiovasc Diabetol. 2013;12(1):31.

91. Orchard TJ, Backlund JC, Costacou T, Cleary P, Lopes-Virella M, Levy AP, et al. Haptoglobin 2-2 genotype and the risk of coronary artery disease in the Diabetes Control and Complications Trial/
Epidemiology of Diabetes Interventions and Complications study (DCCT/EDIC). J Diabetes Complicat. 2016;30(8):1577-84.

92. Qi L, Qi Q, Prudente S, Mendonca C, Andreozzi F, di Pietro N, et al. Association between a genetic variant related to glutamic acid metabolism and coronary heart disease in individuals with type 2 diabetes. JAMA. 2013;310(8):821-8.

93. Prudente S, Shah H, Bailetti D, Pezzolesi M, Buranasupkajorn P, Mercuri L, et al. Genetic variant at the GLUL locus predicts allcause mortality in patients with type 2 diabetes. Diabetes. 2015;64(7):2658-63.

94. Look AHEAD Research Group. Prospective association of GLUL rs10911021 with cardiovascular morbidity and mortality among individuals with type 2 diabetes: the Look AHEAD study. Diabetes. 2016;65(1):297-302.

95. Shah HS, Gao H, Morieri ML, Skupien J, Marvel S, Pare G, et al. Genetic predictors of cardiovascular mortality during intensive glycemic control in type 2 diabetes: findings from the ACCORD clinical trial. Diabetes Care. 2016;39(11):1915-24. GWAS on cardiovascular mortality in intensively treated diabetic subjects.

96. Deloukas P, Kanoni S, Willenborg C, Farrall M, Assimes TL, Thompson JR, et al. Large-scale association analysis identifies new risk loci for coronary artery disease. Nat Genet. 2013;45(1): 25-33.

97. CARDIoGRAMplusC4D Consortium. A comprehensive 1000 genomes-based genome-wide association meta-analysis of coronary artery disease. Nat Genet. 2015;47(10):1121-30. The largest GWAS to date on CVD in the general population.

98. Qi L, Parast L, Cai T, Powers C, Gervino EV, Hauser TH, et al. Genetic susceptibility to coronary heart disease in type 2 diabetes: 3 independent studies. J Am Coll Cardiol. 2011;58(25):2675-82.

99. Raffield LM, Cox AJ, Carr JJ, Freedman BI, Hicks PJ, Langefeld $\mathrm{CD}$, et al. Analysis of a cardiovascular disease genetic risk score in the Diabetes Heart Study. Acta Diabetol. 2015;52(4):743-51.

100. Cox AJ, Hsu FC, Ng MC, Langefeld CD, Freedman BI, Carr JJ, et al. Genetic risk score associations with cardiovascular disease and mortality in the Diabetes Heart Study. Diabetes Care. 2014;37(4):1157-64.

101. Broadbent HM, Peden JF, Lorkowski S, Goel A, Ongen H, Green $\mathrm{F}$, et al. Susceptibility to coronary artery disease and diabetes is encoded by distinct, tightly linked SNPs in the ANRIL locus on chromosome 9p. Hum Mol Genet. 2008;17(6):806-14.

102. Doria A, Wojcik J, Xu R, Gervino EV, Hauser TH, Johnstone MT, et al. Interaction between poor glycemic control and 9p21 locus on risk of coronary artery disease in type 2 diabetes. JAMA. 2008;300(20):2389-97.

103. Hagg S, Thorn LM, Putaala J, Liebkind R, Harjutsalo V, Forsblom $\mathrm{CM}$, et al. Incidence of stroke according to presence of diabetic nephropathy and severe diabetic retinopathy in patients with type 1 diabetes. Diabetes Care. 2013;36(12):4140-6.

104. Bellenguez C, Bevan S, Gschwendtner A, Spencer CC, Burgess AI, Pirinen M, et al. Genome-wide association study identifies a variant in HDAC9 associated with large vessel ischemic stroke. Nat Genet. 2012;44(3):328-33.

105. Jude EB, Oyibo SO, Chalmers N, Boulton AJ. Peripheral arterial disease in diabetic and nondiabetic patients: a comparison of severity and outcome. Diabetes Care. 2001;24(8):1433-7.

106. Helgadottir A, Thorleifsson G, Magnusson KP, Grétarsdottir S, Steinthorsdottir V, Manolescu A, et al. The same sequence variant on 9p21 associates with myocardial infarction, abdominal aortic aneurysm and intracranial aneurysm. Nat Genet. 2008;40(2):21724.

107. Van Zuydam NR, De Andrade M, Vlacholpoulou E, Ahlqvist E, Fagerholm E, Salomaa V, et al. Differential genetic susceptibility to peripheral arterial disease in subjects with and without diabetes. 
Diabetes. 2015;64(S1):A15. Meeting abstract at the American Diabetes Association, 75th scientific sessions, Boston.

108. Rayner NW, Ahlqvist E, Deshmukh H, Van Zuydam N, Sandholm $\mathrm{N}$, Ladenvall $\mathrm{C}$, et al. Genome-wide association studies of diabetic kidney disease in patients with type 2 diabetes. Diabetologia. 2015;58:S200. Meeting abstract at the 51st European Association for the Study of Diabetes Annual Meeting, Stockholm, Sweden.
109. Todd JN, Salem R, Sandholm N, Valo EA, Hiraki LT, Di Liao C, et al. Novel genetic determinants of diabetic kidney disease. Diabetes. 2016;65(S1):A100. Meeting abstract at the American Diabetes Association, 76th scientific sessions, New Orleans.

110. Haukka J, Sandholm N, Toppila I, Valo EA, Forsblom C, Groop P. Pedigree-based analysis of diabetic nephropathy in T1D patients. Diabetes. 2016;65(S1):A73. Meeting abstract at the American Diabetes Association, 76th scientific sessions, New Orleans. 